\title{
Recent Progress of Blockchain Initiatives in Government
}

\author{
A Review of Asian Countries
}

\author{
Faizura Haneem ${ }^{1}$, Hussin Abu Bakar², Nazri Kama ${ }^{3}$, Nik Zalbiha Nik Mat ${ }^{4}$, Razatulshima Ghazali ${ }^{5}$, Yasir Mahmood ${ }^{6}$ \\ ICT Consulting Division, Malaysian Administrative Modernisation and Management Planning Unit (MAMPU), Malaysia ${ }^{1,2,4,5}$ \\ Razak Faculty of Technology and Informatics, Universiti Teknologi Malaysia, Kuala Lumpur, Malaysia ${ }^{3,6}$ \\ Department of Software Engineering, Faculty of Information Technology ${ }^{6}$
}

The University of Lahore, Lahore, Pakistan ${ }^{6}$

\begin{abstract}
Blockchain is a decentralized and distributed ledger technology that aims to ensure transparency, data security, and integrity. There are rising interest and investment by the governments and industries in Blockchain to deliver significant cost savings and increase efficiency. Identifying Blockchain initiatives that are currently implemented in the government world-wide could improve understanding as well as set benchmarks for specific countries. However, although some review studies on Blockchain initiatives have been carried out, there are very few studies that uncover Blockchain initiatives implemented by the government in Asian countries. Hence, this study reviews Blockchain initiatives in the five-top e-government development index (EGDI) countries in Asia; South Korea, Singapore, Japan, United Arab Emirates, and Cyprus. We strategized our review methods by utilizing relevant keyword searches in existing literature, books, academic journals, conferences, and industrial reports. The results of this study will help other researchers and practitioners to recognize the current stage of Blockchain initiatives in the government of Asian countries.
\end{abstract}

Keywords-Blockchain initiatives; governments; review

\section{INTRODUCTION}

Blockchain technology is a distributed database that stores data of digital assets and transactions across a peer-to-peer network. Blockchain is used in a modern and innovative way to secure, store, and distribute the data [1]. The data in Blockchain are secured through a chain of blocks that are cryptographically linked together [2]. Unlike a centralized implementation of the Relational Database Management System (RDBMS), Blockchain stores the data in multiple nodes, and this mechanism is called distributed open-ledger [3]. This disruptive technology is expected to change many existing business models or make new ones that could generate significant impacts on entire industries.

This cryptographic link of the records in Blockchain makes the data immutable and traceable whereby once it has been created in the Blockchain, modification is not allowed. This would prevent the data from any forge [1]. Additionally, by storing the data in distributed open ledgers in the whole network, it is almost impossible to tamper and the need for a central entity is no longer necessary [4]. Miner or sealer nodes across the peer-to-peer network are responsible for the validity of the data via a consensus mechanism without any central entity control. The decentralized architecture of Blockchain could also increase efficiency and avoid a single point of failure [1]. In the nutshell, Blockchain could be considered as a data infrastructure that provides security, immutability, and traceability of the records, with high-efficiency and highreliability of the system.

There are rising interest and investment by the government and industries in Blockchain to deliver significant cost savings and increase efficiency. A report by United Nations [5] stated that there are potential applications of Blockchain in government from identity management, registries, evidence management system, energy and water exchange, to taxes and remittances [5], [6]. Besides, Blockchain could also facilitate Internet-of-Things implementation by enabling the sharing of information and resources that would establish a demand for services between devices [7], [8]. Currently, many pilot projects have been reported [9] in this regard as it could be a tool for governments to improve transparency, prevent fraud, and build trust in the public sector.

In current state-of-the-art, although some review studies on Blockchain initiatives have been carried out, there are very few studies that uncover Blockchain initiatives by the government, particularly in Asian countries context. Since Blockchain is a relatively new and emerging technology, prior studies mostly focus on reviewing the challenges of Blockchain adoption and technical capabilities [4], [10], [11]. In regards to government, a review study by [12] concentrates on current Blockchain architecture applied in the government, and a study by [13] focuses on consensus protocols of Blockchain in the Public Sector. Meanwhile, a study by [10] systematically review challenges of Blockchain adoption by government organizations, and a study by [14] analyses Blockchain initiatives in the public sector but it only focuses on D5 countries Digital 5 (D5) countries which include United Kingdom, United States, Estonia, New Zealand, and Israel. On the other hand. Hence, this paper attempts to address the gap by reviewing recent Blockchain initiatives in the government of Asian countries.

This study reviews Blockchain initiatives in the government of five countries in Asia which have achieved a Very High E-Government Development Index (EGDI) based on the United Nations evaluation in 2020 [15] which are South Korea, Singapore, Japan, Cyprus, and the United Arab 
Emirates (UAE), with the EGDI of 0.9560, 0.9150, 0.8989, $0.8731,0.8555$, respectively. This study may guide future researchers and practitioners wishing to embark on Blockchain initiatives especially in the context of government.

The remainder of the paper is organized as follows: Section II presents an overview of the Blockchain concepts; Section III describes the study methodology; Section IV presents the review results and analysis; Section V discusses the results and findings and finally conclusion and recommendations are drawn in Section VI.

\section{LITERATURE REVIEW}

Recently, more governments join the race to keep pace with the global movement of Blockchain adoption by approaching regulatory legislation and launching pilot projects every day. Governments and public sector organizations are using Blockchain technology to step away from siloed and inefficient centralized structures. Current centralized systems appear expensive and highly-complex, whereas Blockchain is expected to provide more stable, scalable, and cost-effective architectures. Among the main characteristics of Blockchain which could significantly transform the government is as follows:

1) Immutability: Blockchain is a registry of encrypted digital records or transactions called blocks. Every block is then "chained" to the next block, in linear and sequential order, utilizing a cryptographic signature [16]. The Blockchain is a block sequence containing a full list of transaction records whereby each data block is time stamped and linked in chronological order via a cryptographic signature [17]. Since immutability can be described as the ability of the Blockchain ledger to remain unchanged and unaltered. This feature of Blockchain makes no one can interact with the system or change the data stored in the blocks.

2) Traceability: Since each of the transactions on the Blockchain is validated and recorded with a timestamp, users can easily verify and trace the previous records by accessing any node in the distributed network. In the Bitcoin Blockchain, each transaction could be traced to previous transactions iteratively. It improves the traceability and the auditability of the data stored in the Blockchain.

3) Persistency: Since each of the transactions spreading across the network needs to be confirmed and recorded in blocks distributed in the whole network, it is nearly impossible to tamper. Additionally, each broadcasted block would be validated by other nodes and transactions would be checked. Hence, any falsification could be detected easily.

4) Decentralized: In traditional centralized transaction systems, each transaction must be checked by a central trusted entity (e.g. a central bank) which inevitably results in cost and performance bottlenecks on central servers. Differently, a transaction in the Blockchain network can be carried out through a decentralized method between any two peers (P2P) without being authenticated by the central agency. Blockchain can only be changed by consensus between system participants without a central instance and a transaction can never be modified or removed [18]. The elimination of a central instance in a decentralized network of Blockchain means a drastic change to direct transactions between nonintermediaries or intermediary services [19].

\section{STUDY METHODOLOGY}

This review paper is designed based on a systematic review methodology for IS research [20]. This study simplified the review protocol, enumerated as follows: 1) research questions; 2) search strategy design; 3) study selection; and 4) analysis of findings.

\section{A. Research Questions}

Two research questions were formulated: 1) What are the Blockchain initiatives in the government of Asian countries? and 2) How did the initiatives vary by sector?

\section{B. Search Strategy Design}

The study thoroughly searched all published works found in the existing literature, books, academic journals, conferences, government, and industrial reports, searching several databases using keywords. First, this study performed a systematic review of Blockchain initiatives in the chosen countries from a database indexed by Scopus, WoS Core Collection, and several prominent digital government reports. Then, using the snowball method, the study extends the search to government and industrial reports such as OECD Working Papers on Public Governance 2018 [21], Blockchain in Government Tracker by The Illinois Blockchain Initiative [9], and E-Government Survey 2020 by the United Nations [15].

Search Keywords: Consistent with prior research by [22], three steps involved in constructing the search keywords were: 1) Identification of alternative spellings and synonyms for major terms; 2) Identification of keywords in relevant papers or books; and 3) Usage of the Boolean OR to incorporate alternative spellings and synonyms. The initial search strings used were "Blockchain”, “initiatives”, “project”, “intention”, "program”, “government”, "public sector”, "Korea”, "Singapore”, “UAE”, “Japan”, “Cyprus”, “Asia countries”. Then, the search strings were combined using “AND” and "OR" Boolean. The search strings were used in each electronic database to retrieve the publications based on the titles, abstracts, and keywords, depending on the advanced search facility provided by each database.

Search Criteria: Three search criteria were used: 1) the language used in the paper was English; and 2) the paper was categorized under journals, proceedings, books, book chapters, and reports 3) the search process involved retrieval of publications from 2015 to 2020.

\section{Study Selection}

Initially, 814 publications were identified using the search keywords from the selected databases. The search was then extended to the Google Scholar database using the snowball method. This was to ensure that several prominent digital government reports that were not indexed in our selected databases were also considered. From the search, an additional 19 publications were found. 
During the search process, metadata of the initial articles were gathered and indexed. The metadata were: 1) Electronic Repository; 2) Title of the literature; 3) Abstract; 4) Year; 5) Publication Type; and 6) DOI/ISBN/ISSN Number. Based on the metadata, the deduplication process was then performed to eliminate any duplicated copies of the articles [23], [24], which then decreased the number of publications to 587.

Next, a practical screening process was conducted which involved screening the titles and abstracts of the publications to select relevant publications. Then, a quality assessment was conducted against the selected publications by evaluating the criteria. Quality assessment criteria involved the retrieval of the full version of these publications and the context of the studies.

\section{Analysis of Findings}

After conducting the quality assessment, 29 publications were selected for the analysis stage. The following section analyses the findings from these qualified publications.

\section{FINDINGS AND DisCUSSION}

As described earlier, there are two research questions to be answered by this review study. The following sections describe the findings and discussion based on the research questions.

\section{A. What are the Blockchain Initiatives in the Government of Asian Countries?}

Table I represents the Blockchain initiatives in the government of South Korea, Singapore, Japan, Cyprus, and the UAE. The following section describes 30 noticeable initiatives in South Korea, Singapore, Japan, Cyprus, and the UAE.

1) South Korea: South Korea's government is the world leader in online services provision and has the highest EGDI value in Asia has shown a positive movement towards Blockchain [15]. The province of Gyeonggi-do has used a voting system based on Blockchain technology to collect its citizens to vote on community projects. The Seoul Metropolitan Government is developing an ICON project which is expected to incorporate the city-wide initiative's Blockchain applications into the government's core operating IT system used to carry out key administrative activities [9], [25]. The use of ICON for the dissemination of government documents is the first case in which the Government of South Korea used for the Appointment of the Seoul Blockchain Governance [25].

In October 2020. Korea Internet \& Security Agency is expected to implement a Blockchain-powered employee ID system using KISA Coin [26]. KISA Coin tokens are issued to reward the best workers, allowing them to buy snacks, drinks, and even office supplies. It is currently being evaluated as a pilot, with the goal that it will be made available to the entire workforce. Among Blockchain and Cryptocurrency regulations, National Tax Services published its preliminary assessment of taxation on cryptocurrency after its 2017 forum [27].

2) Singapore: The Monetary Authority of Singapore (MAS) implements Project Ubin to explore Blockchain to clear and settle payments and securities. The payment network will provide interfaces for other Blockchain networks to be seamlessly connected and provide additional features such as Delivery-versus-Payment settlement with private exchanges, conditional payments, and trade escrow, and payment obligations for trade finance [9], [28]. Meanwhile, the Singapore Economic Development Board, Monetary Authority of Singapore (MAS) in partnership with IBM has established IBM Blockchain Innovation Centre. It is claimed to be the first Blockchain Innovation Center in the world. The Innovation Center is expected to include both global banks and fintech start-ups, and to develop a range of technology pilots for the finance and commercial industries based on the Linux Foundation Hyperledger platform [9], [29].

On the other hand, the Monetary Authority of Singapore (MAS) has created the R3 Blockchain Legal Centre of Excellence (LCoE) as a forum for the global legal community to get the latest updates and discuss best practices on Blockchain technology and the Corda R3 Blockchain network. Law firms are constantly collaborating with clients to provide specialized advice about how to deal with the legal implications of Blockchain technology, such as structuring Corda business networks and drawing up smart legal contracts [9], [30]. Info-communications and Media Development Authority (IMDA) established TradeTrust which consists of a collection of internationally agreed principles and mechanisms that support the exchange of electronic trading documents. This is done through a distributed Blockchain providing interoperability for linking governments and businesses [9], [31]. IMDA also organized Hackathon Competition in which the participants are challenged to create successful Blockchain-based Minimum Viable Products (MVPs) or Proofs-of-Concept (POCs) solutions to industry-related challenges [9], [32].

In the education sector, Ngee Ann Polytechnic (NP) uses Blockchain to check the validity of the polytechnic diplomas the first public institute of education that uses Blockchain in that manner in Singapore [33]. While Singapore Customs Authority developed the National Trade Platform (NTP) - The new national trading platform will replace the existing TradeNet and TradeXchange platforms for the declaration of permits and other facilities for trade and logistics [33]. In terms of regulations, Singapore has a balanced Blockchain and Cryptocurrency foster by the Monetary Authority of Singapore in taxation and money transmission law [27].

3) Japan: The Ministry of Economy, Trade, and Industry in Japan has developed a Blockchain assessment methodology or form. It is claimed to be the first type of evaluation of Blockchain-based systems taking into account comparability with existing systems \& comprehensibility and by analyzing the tradeoff between assessment items [9], [34]. Besides, the ministry also conducted a Survey on Blockchain technologies 
to universities and research institutes in studying the applicability of Blockchain technology. It is used to facilitate the mobility of domestic and foreign human resources and safe reliability of research results as well as research for the development of standards [9], [35]. The Ministry of Justice has developed Land's Blockchain-based central repository of land and property registration [9], [36].
Meanwhile, the Ministry of Internal Affairs and Communications has developed a Blockchain-Based Tendering System is expected to assist both the private sector and the government to apply for tenders. Applicants would receive the tax payment certificates and other required documentation from different government agencies using Blockchain [9], [37]. About regulations, the Financial Services Agency of Japan has established Blockchain and Cryptocurrency Regulation in Japan [9], [27].

TABLE I. BLOCKCHAIN INITIATIVES IN THE GOVERNMENT OF ASIAN COUNTRIES

\begin{tabular}{|c|c|c|c|c|c|}
\hline No. & Country & Government Entity & Initiative Name & Sector & Source \\
\hline 1. & South Korea & Gyeonggi-do Province & Local Government Voting & Social & [9], [48] \\
\hline 2. & South Korea & Seoul Metropolitan Government & Blockchain Strategy & Inter-Sector & [9], [15], [49] \\
\hline 3. & South Korea & Seoul Metropolitan Government & $\begin{array}{l}\text { Appointment of the Seoul Blockchain } \\
\text { Governance }\end{array}$ & Inter-Sector & {$[25]$} \\
\hline 4. & South Korea & Korea Internet \& Security Agency & Blockchain-powered employee ID system & Administration & {$[26]$} \\
\hline 5. & South Korea & Financial service agencies in South Korea & Blockchain and Cryptocurrency Regulation & Financial & {$[27]$} \\
\hline 6. & Singapore & Monetary Authority of Singapore (MAS) & Project Ubin & Financial & $\begin{array}{l}\text { [9], [15], [21], } \\
\text { [28] }\end{array}$ \\
\hline 7. & Singapore & $\begin{array}{l}\text { Singapore Economic Development Board, } \\
\text { Monetary Authority of Singapore (MAS) }\end{array}$ & IBM Blockchain Innovation Centre & Financial & [9], [29] \\
\hline 8. & Singapore & Monetary Authority of Singapore (MAS) & $\begin{array}{l}\text { R3 Blockchain Legal Centre of Excellence } \\
\text { (LCoE) }\end{array}$ & Financial & [9], [21], [30] \\
\hline 9. & Singapore & $\begin{array}{l}\text { Info-communications and Media } \\
\text { Development Authority (IMDA) }\end{array}$ & Trade Trust & Financial & [9], [31] \\
\hline 10. & Singapore & $\begin{array}{l}\text { Info-Communications and Media } \\
\text { Development Authority (IMDA) }\end{array}$ & $\begin{array}{l}\text { Hackathon Competition: Securing IoT Devices } \\
\text { with Blockchain }\end{array}$ & Inter-Sector & [9], [32] \\
\hline 11. & Singapore & Ngee Ann Polytechnic (NP) & Academic credential & Education & {$[33]$} \\
\hline 12. & Singapore & Singapore Customs Authority & National Trade Platform (NTP) & Supply-Chain & {$[33]$} \\
\hline 13. & Singapore & Financial service agencies in South Singapore & Blockchain and Cryptocurrency Regulation & Financial & {$[27]$} \\
\hline 14. & Japan & Ministry of Economy, Trade and Industry & Blockchain Assessment Methodology/Form & Inter-Sector & [9], [34] \\
\hline 15. & Japan & Ministry of Economy, Trade and Industry & $\begin{array}{l}\text { Survey on Blockchain Technologies and Related } \\
\text { Services }\end{array}$ & Inter-Sector & [9], [35] \\
\hline 16. & Japan & Ministry of Justice & Blockchain-based Land Registry & Land & [9], [36] \\
\hline 17. & Japan & $\begin{array}{l}\text { Ministry of Internal Affairs and } \\
\text { Communications }\end{array}$ & Blockchain-Based Tendering System & Supply Chain & [9], [37] \\
\hline 18. & Japan & Financial service agencies in Japan & Blockchain and Cryptocurrency Regulation & Financial & [9], [27] \\
\hline 19. & Cyprus & Minister of Finance & National Strategy for Cyprus & Inter-Sector & [9], [38] \\
\hline 20. & Cyprus & Financial Services Agency of Cyprus & $\begin{array}{l}\text { Cryptocurrency Regulation, Sales Regulation, } \\
\text { Money Transmission Law }\end{array}$ & Financial & {$[27]$} \\
\hline 21. & Cyprus & University of Nicosia & Block-Chain Verified Certificates & Education & {$[35],[50]$} \\
\hline 22. & UAE & The Emirates Blockchain Strategy 2021 & Emirates \& Dubai Blockchain Strategy & Inter-Sector & $\begin{array}{l}\text { [9], [15], [40], } \\
\text { [41] }\end{array}$ \\
\hline 23. & UAE & Financial service agencies in UAE & $\begin{array}{l}\text { Cryptocurrency Regulation, Sales Regulation, } \\
\text { Taxation }\end{array}$ & Financial & {$[27]$} \\
\hline 24. & UAE & Dubai Customs, Dubai Trade & Blockchain powered E-commerce Platform & Supply Chain & [9], [42] \\
\hline 25. & UAE & Dubai Immigration and Visas Department & $\begin{array}{l}\text { Biometric verification with Blockchain } \\
\text { technology }\end{array}$ & Immigration & [9], [43] \\
\hline 26. & UAE & Dubai Future Foundation & Global Blockchain Council & Inter-Sector & [9], [21], [44] \\
\hline 27. & UAE & Smart Dubai Office & Global Blockchain Challenge & Inter-Sector & [9], [45] \\
\hline 28. & UAE & $\begin{array}{l}\text { Dubai Healthcare City Authority and the } \\
\text { Dubai Health Authority (DHA) }\end{array}$ & Health Smart Licensing & Healthcare & [9], [46] \\
\hline 29. & UAE & Dubai Multi Commodities Centre (DMCC) & Securing the Diamond Trade & Supply Chain & [9], [47] \\
\hline 30. & UAE & Roads and Transport Authority (RTA) & Vehicle history Blockchain project & Transportation & [41] \\
\hline
\end{tabular}


4) Cyprus: The Minister of Finance in Cyprus has established the National Strategy for Cyprus in 2019. The goal of the national strategy is to encourage the advancement of this technology through innovation and pilot applications, through close cooperation between the public and private sectors [9], [38]. The University of Nicosia, Cyprus has established an open standard for verifying academic certificates on the Blockchain [39]. In terms of regulations, Cyprus has established Blockchain and Cryptocurrency Regulation in Japan including [27] Cryptocurrency Regulation, Sales Regulation, Money Transmission Law.

5) United Arab Emirates: The UAE has established The Emirates Blockchain Strategy 2021. The strategy uses three strategic pillars Government Efficiency, Industry Creation, and International Leadership to make "Dubai the first city fully powered by Blockchain by 2020" [9], [40], [41]. The Dubai Customs, Dubai Trade has formed a Blockchainpowered E-commerce Platform - The latest Blockchain-based project, which aims to help the emirate become a global ecommerce center and enable e-commerce companies to set up their businesses in Dubai [9] [42]. Meanwhile, the Dubai Immigration and Visas Department has combining biometric authentication and Blockchain technology to develop digital passports for seamless entry at Dubai Airport [9], [43]. The Global Blockchain Council was formed by Dubai Future Foundation to examine, discuss current and future applications, and coordinate transactions through the Blockchain platform [9], [44].

Smart Dubai Office has organized the Global Blockchain Challenge which has received 700 applications from 79 countries around the world in 2019. The participated projects covered 20 different fields, including, but not limited to, real estate, asset management, payments, energy, education, healthcare, and supply chain management [9], [45]. In healthcare, the Dubai Healthcare City Authority and the Dubai Health Authority (DHA) decided to connect the licensing data of healthcare professionals with a Blockchain system in 2018. It enables potential healthcare providers to apply from anywhere in the world to receive a license [9], [46]. In securing the Diamond Trade, Dubai Multi Commodities Centre (DMCC) has announced the launch of its ecosystem in the Crypto Valley [9], [47].

While in transportation management, the Roads and Transport Authority (RTA) is implementing a Vehicle history Blockchain project. The project aims to provide a transparent record of the vehicle's past from the manufacturer to the scrap yard including car makers, dealers, regulators, insurance firms, buyers, sellers, and garages [41]. With regards to regulations, the Financial Services Agency of Japan has established Blockchain and Cryptocurrency Regulation in Japan including Cryptocurrency Regulation, Sales Regulation, Taxation, Money Transmission Law [9], [27].

\section{B. How did the Initiatives Vary by Sector?}

Blockchain initiatives and implementation in the Asian countries could be tracked through several sectors - Intersector, Financial, Supply Chain, Education, Administration,
Immigration, Healthcare, Land, Transportation, and Social. The Tree-map analysis in Fig. 1 shows the fraction of Blockchain initiatives by sectors. Based on this categorization, it could guide and create a lesson learned for other researchers and practitioners.

1) Inter-sector Initiatives: Inter-sector initiatives include programs that have been implemented by the government that beneficial across all sectors such as financial, education, healthcare, and supply chain. These programs play a fundamental role to foster Blockchain initiatives in all sectors. Among vital inter-sector initiatives involves Blockchain strategy or master plan, council or governance, hackathon competition, assessment model, and survey on Blockchain.

As indicated in Fig. 2, this study revealed three countries South Korea [49], Cyprus [38], and UAE [40] have published on their Blockchain Strategy in 2019, 2019, and 2018 respectively. The establishment of the Blockchain strategy sets out a roadmap for the launch of Blockchain technology and will provide economic opportunities for all sectors. Blockchain council or governance also being formed in South Korea [25] and Dubai [9], [44] as part of the efforts to embrace the new developments and practices of Blockchain at a global level. The Blockchain council or governance is intended to discover, confer current, and future applications of Blockchain in the country which consists of potential main players in the Blockchain industry. It incorporates government agencies, private companies, leading banks, free zones, and international Blockchain technology firms.

The study also discovered Hackathon competitions were organized in Singapore [9], [32], and Dubai [9], [45] on an annual basis. The Hackathon competitions were held to encourage technology understanding and adoption and inspire businesses to pursue creativity of the business model resulting from Blockchain and other emerging technology. Meanwhile, in Japan, assessment methodology and survey on Blockchain have been conducted in producing reusable evaluation form intended to be used not only to equate a traditional system with a Blockchain-based system but also to compare various Blockchain-based systems [34].

2) Financial: Regarding the financial sector, all five countries have already embarked on cryptocurrency regulation comprised of standard terms, sales regulation, taxation, and anti-money laundering laws. According to [51], as cryptocurrency seems to be a disruptor to conventional currency, regulations should be set up to prevent criminal misuse of this disruptive technology. Law enforcement must be proactively approached, and regulatory agencies are expected to inform the related agencies about how cryptocurrencies function, provide technical assistance, and promote discussion about topics of common concern.

Singapore has shown interest in the financial sector which explores Blockchain to clear and settle payments and securities through the project called Project Ubin and established the Innovation Center which includes both global banks and fintech start-ups. As the Blockchain is the backbone of the cryptocurrency such as Bitcoin and Ethereum, financial 
firms are trying to cope with this technology due to high increase in demand for financial services and the enormous increase in competition worldwide in the financial sector [52].

3) Supply Chain and Immigration: Fig. 1 shows that three countries have developed programs in this sector in tracking the declaration of permits and other facilities for trade and logistics in Singapore [33], tender application in Japan [9], [37], and managing identity via biometric authentication in Dubai [9], [44]. This indicates that supply chain and immigration are among the potential sectors for Blockchain implementation.

4) Education and Healthcare: The analysis result also pointed out that the two countries have organized programs under Healthcare and education. In 2018, UAE has a collaboration with the Estonian company to develop a Blockchain-based licensing system that stores healthcare professional licenses [9], [46]. Estonia has used Blockchain as an extra layer of security to ensure the integrity of health records since 2016 [53]. In the meantime, through Blockchain,
Singapore has demonstrated an educational initiative with academic credentials [33]. This means that among possible sectors for the adoption of Blockchain are healthcare and education.

5) Administration, Social, Land and Transportation: Other sectors that the Asian countries have embarked on Blockchain initiatives are Administration, Social, Land \& Transportation. Realizing the advantages of Blockchain in improving efficiency, the Korean government has used this opportunity for the implementation of the employee system which is expected to be rolling out to the entire workforce [26]. With regards to social, a Blockchain-based voting system has been implemented in Gyeonggi-do Province which has increased the transparency of the voting result [48]. Meanwhile, Japan already working on a Blockchain-based Land Registry since 2018 [9], [36], and a Blockchain-based transportation tracking system has been developed by the UAE Roads and Transport Authority which aims to provide transparent records of the vehicle's history [41].

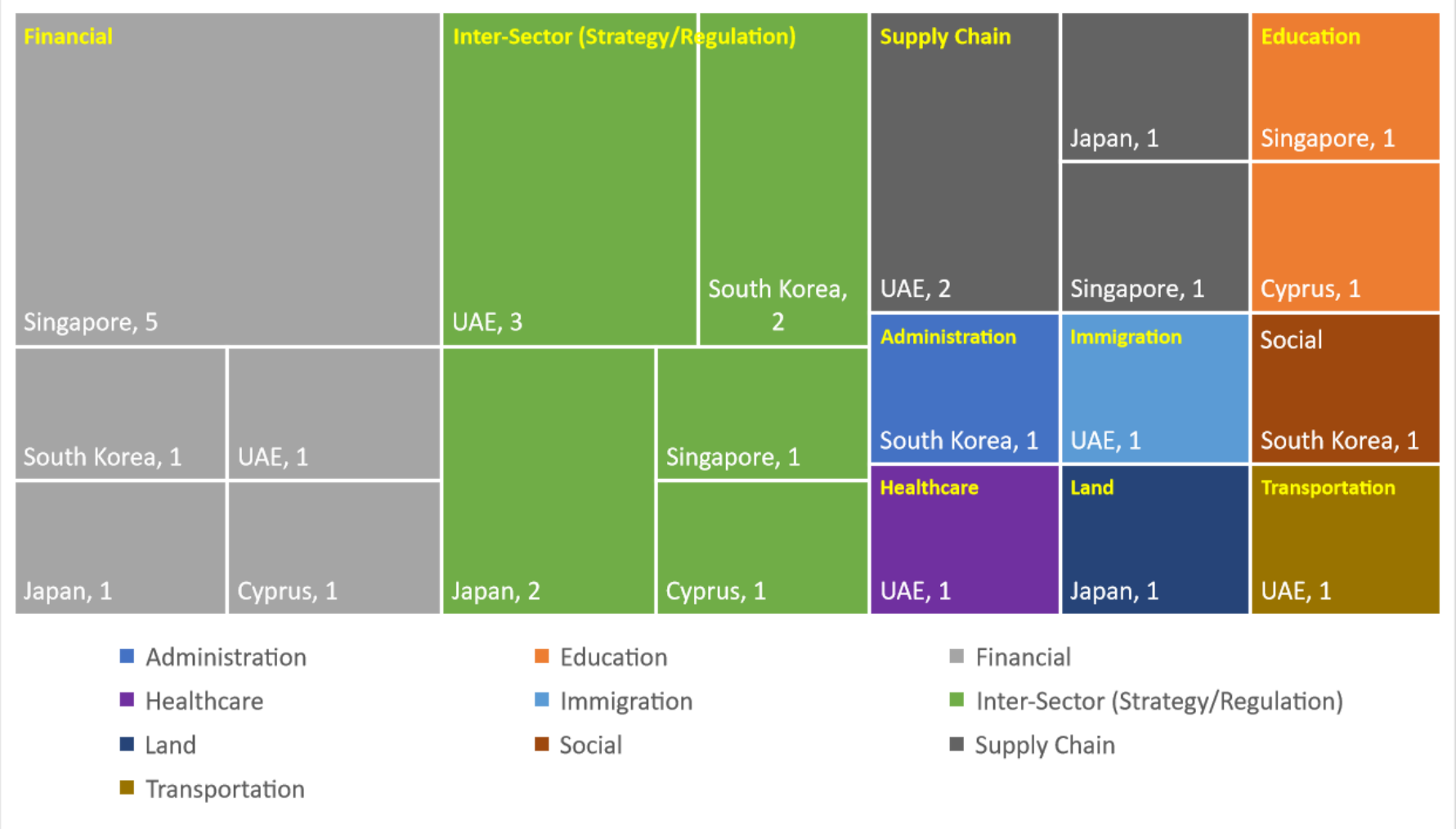

Fig. 1. Blockchain Initiatives by the Government in Asian Countries. 


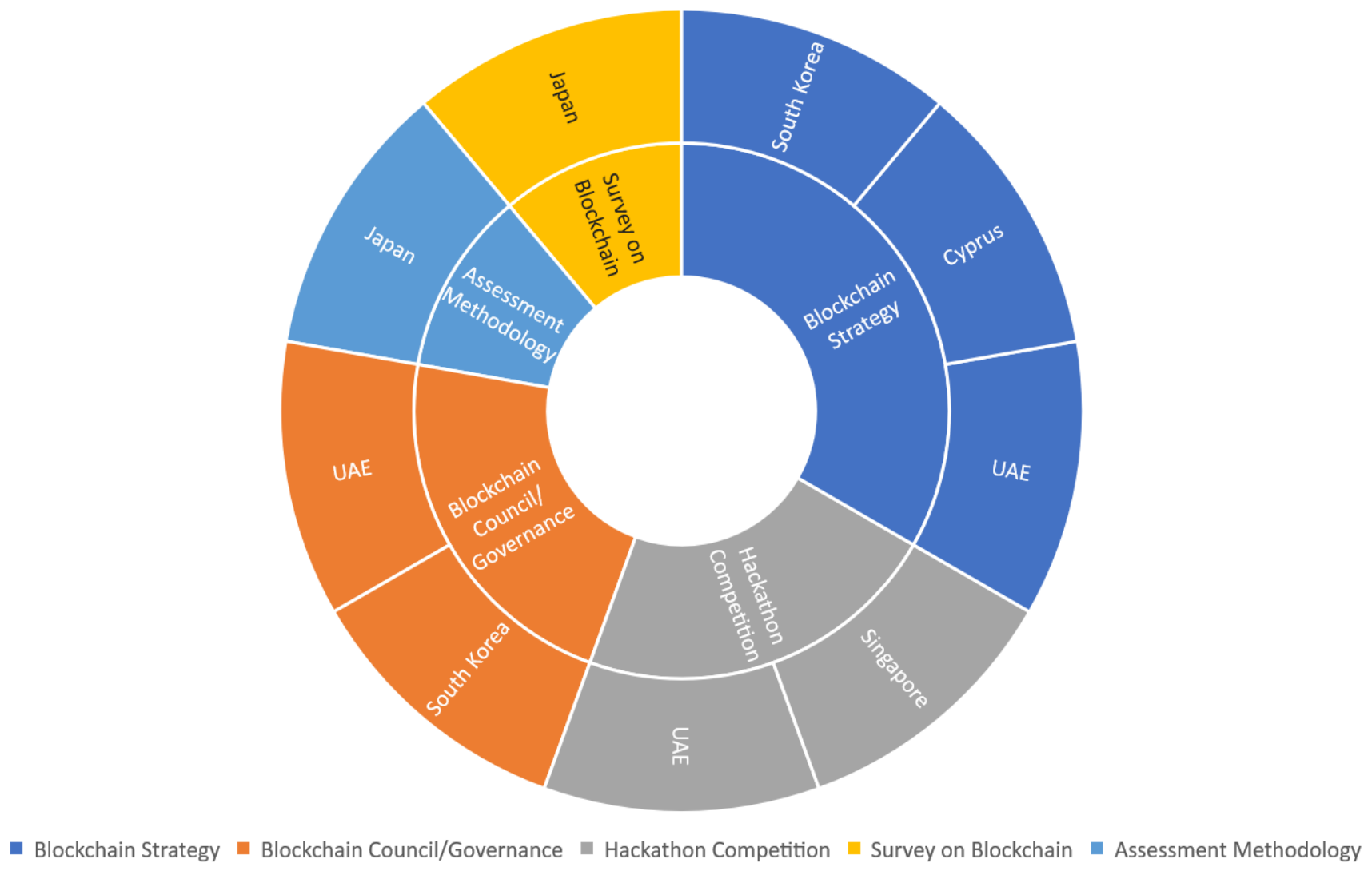

Fig. 2. Inter-Sector Blockchain Initiatives by the Government in Asian Countries.

\section{CONCLUSION}

To conclude, this study has achieved the aims to review Blockchain initiatives in the government of five countries in Asia that have achieved a Very High E-Government Development Index (EGDI) based on the United Nations evaluation in 2020. This study has been one of the first attempts to thoroughly review recent literature on Blockchain applications and initiatives by the government in Asian countries. This study has highlighted prominent Blockchain initiatives implemented by the government entities in these countries. Among noticeable sectors are financial, supply chain, immigration, education, healthcare, administration, social, land \& transportation. This study has identified that the national strategy, Blockchain council, and innovation center establishment are important to set out a roadmap and to sustain the Blockchain initiatives in a long run. Besides, introducing standard methodology or guidelines, and appropriate laws and regulations are important to strengthening the process of supporting Blockchain implementation by the public sector. Additionally, the skill development programs and the organization of competition i.e. Hackathon are also vital to encourage Blockchain understanding and adoption. For future work, further studies should thoroughly review recent progress in other Asian countries to compare the movement of this disruptive technology. This study could guide and provide researchers and practitioners with the success stories and lessons learnt of the Blockchain initiatives by the government in Asian countries.

\section{ACKNOWLEDGMENT}

The study is financially sponsored by Fundamental Research Grant, vote no. 21H12, Universiti Teknologi Malaysia.

\section{REFERENCES}

[1] M. Pilkington, "Blockchain technology: principles and applications," in Research handbook on digital transformations, Edward Elgar Publishing, 2016.

[2] D. Drescher, Blockchain basics, vol. 276. Springer, 2017.

[3] M. Nofer, P. Gomber, O. Hinz, and D. Schiereck, “Blockchain,” Bus. Inf. Syst. Eng., vol. 59, no. 3, pp. 183-187, 2017.

[4] M. Crosby, P. Pattanayak, S. Verma, V. Kalyanaraman, and others, "Blockchain technology: Beyond bitcoin," Appl. Innov., vol. 2, no. 610, p. 71, 2016.

[5] U. Nations, “E-Government Survey 2018,” 2018.

[6] A. Government, “The National Blockchain Roadmap,” 2019.

[7] T. Ahram, A. Sargolzaei, S. Sargolzaei, J. Daniels, and B. Amaba, "Blockchain technology innovations," in 2017 IEEE Technology \& Engineering Management Conference (TEMSCON), 2017, pp. 137-141.

[8] K. Christidis and M. Devetsikiotis, "Blockchains and smart contracts for the internet of things," IEEE Access, vol. 4, pp. 2292-2303, 2016.

[9] Illinois, "Blockchain in Government Tracker." [Online]. Available: https://airtable.com/universe/expsQEGKoZO2lExKK/blockchain-ingovernment-tracker. [Accessed: 08-Apr-2020].

[10] F. R. Batubara, J. Ubacht, and M. Janssen, "Challenges of blockchain technology adoption for e-government: a systematic literature review," in Proceedings of the 19th Annual International Conference on Digital Government Research: Governance in the Data Age, 2018, pp. 1-9.

[11] J. Yli-Huumo, D. Ko, S. Choi, S. Park, and K. Smolander, "Where is current research on blockchain technology?-a systematic review," PLoS One, vol. 11, no. 10, p. e0163477, 2016. 
[12] E. A. Franciscon, M. P. Nascimento, J. Granatyr, M. R. Weffort, O. R. Lessing, and E. E. Scalabrin, "A Systematic Literature Review of Blockchain Architectures Applied to Public Services,” in 2019 IEEE 23rd International Conference on Computer Supported Cooperative Work in Design (CSCWD), 2019, pp. 33-38.

[13] A. Shahaab, B. Lidgey, C. Hewage, and I. Khan, "Applicability and Appropriateness of Distributed Ledgers Consensus Protocols in Public and Private Sectors: A Systematic Review," IEEE Access, vol. 7, pp. 43622-43636, 2019.

[14] A. Ojo and S. Adebayo, "Blockchain as a Next Generation Government Information Infrastructure: A Review of Initiatives in D5 Countries," Springer Int. Publ., vol. 32, pp. 283-298, 2017.

[15] UN, “UN E-Government Survey 2020,” 2020.

[16] S. Bogart and K. Rice, "The blockchain report: welcome to the internet of value,” Needham Insights, 2015.

[17] D. L. K. Chuen, Handbook of digital currency: Bitcoin, innovation, financial instruments, and big data. Academic Press, 2015.

[18] K. Fanning and D. P. Centers, "Blockchain and its coming impact on financial services,” J. Corp. Account. Financ., vol. 27, no. 5, pp. 53-57, 2016.

[19] D. Tapscott and A. Tapscott, Blockchain revolution: how the technology behind bitcoin is changing money, business, and the world. Penguin, 2016.

[20] C. Okoli and K. Schabram, "Working Papers on Information Systems A Guide to Conducting a Systematic Literature Review of Information Systems Research,” Sprout Work. Pap. Inf. Syst., vol. 10, no. 26, pp. 151, 2010.

[21] A. H. Jamie Berryhill, Théo Bourgery, "Blockchains Unchained: Blockchain Technology and its Use in the Public Sector," 2019.

[22] B. Kitchenham and S. Charters, "Guidelines for performing Systematic Literature Reviews in Software Engineering," Tech. Rep. EBSE-200701, 2007.

[23] Q. He, Z. Li, and X. Zhang, "Data deduplication techniques," in Future Information Technology and Management Engineering (FITME), 2010 International Conference, 2010, vol. 1, pp. 430-433.

[24] F. Haneem, N. Kama, R. Ali, and A. Selamat, "Applying Data Analytics Approach in Systematic Literature Review: Master Data Management Case Study,” Front. Artif. Intell. Appl., vol. 297, pp. 705-715, 2017.

[25] J. Young, "Here's How the Gov't of Seoul is Using a Public Blockchain in the Real-World.” [Online]. Available: https://www.ccn.com/hereshow-the-govt-of-seoul-is-using-a-public-blockchain-in-the-real-world/. [Accessed: 05-Oct-2020].

[26] F. Erazo, "South Korean government agency to use blockchain-based employee ID system.” [Online]. Available: https://cointelegraph. com/news/south-korean-government-agency-to-use-blockchain-basedemployee-id-system.

[27] GLI, "Blockchain \& Cryptocurrency Regulation,” 2020. [Online]. Available: https://www.globallegalinsights.com/practice-areas/blockchai n-laws-and-regulations/japan\#chaptercontent2.

[28] MAS, "Project Ubin: Central Bank Digital Money using Distributed Ledger Technology.” [Online]. Available: https://www.mas.gov.sg/ schemes-and-initiatives/project-ubin.

[29] A. Mizrahi, "Singapore Government Joins IBM to Create Blockchain Innovation Center.” [Online]. Available: https://www.financemagnates. com/cryptocurrency/innovation/singapore-government-joins-ibm-tocreate-blockchain-innovation-center/. [Accessed: 05-Oct-2020].

[30] R3, Can Blockchain Future-Proof Supply Chains? - A Brexit Case Study. 2019.

[31] IMDA, “TradeTrust.” [Online]. Available: https://www.imda.gov.sg/ programme-listing/international-trade-and-logistics/tradetrust.

[32] IMDA, "Blockchain Challenge.” [Online]. Available: https:// www.imda.gov.sg/programme-listing/blockchain-challenge. [Accessed: 05-Oct-2020].
[33] C. Lago, "How Singapore is using blockchain outside of cryptocurrencies.” [Online]. Available: https://www.cio.com/article/ 3291758/how-singapore-is-using-blockchain-outside-of-cryptocurrencies.html.

[34] METI, "Document Titled 'Evaluation Forms for Blockchain-based Systems ver. 1.0' Released,” 2017. [Online]. Available: https://www. meti.go.jp/english/press/2017/0329_004.html. [Accessed: 05-Oct-2020].

[35] METI, “FY 2018 Industrial Technology Survey,” 2019.

[36] M. Gonzalez, "Blockchain in Japan,” 2018.

[37] Nikkei-Asia, "Japan looks to blockchains for more secure e-government systems,” 2017. [Online]. Available: https://asia.nikkei.com/Business/ Biotechnology/Japan-looks-to-blockchains-for-more-secure-egovernment-systems. [Accessed: 05-Oct-2020].

[38] R. of Cyprus, “A National Strategy for Cyprus,” 2019.

[39] UNIC, "Blockchain Certificates." [Online]. Available: https://www. unic.ac.cy/iff/blockchain-certificates/. [Accessed: 11-Oct-2020].

[40] "Smart Dubai Blockchain.” [Online]. Available: https://www. smartdubai.ae/initiatives/blockchain. [Accessed: 06-Oct-2020].

[41] UAE, "Blockchain in the UAE government," 2020. [Online]. Available: https://u.ae/en/about-the-uae/digital-uae/blockchain-in-the-uaegovernment. [Accessed: 11-Oct-2020].

[42] N. Lung, "Dubai launches world's first B2B Smart Commerce Platform for Free Zones," 2018. [Online]. Available: https://opengovasia .com/dubai-launches-worlds-first-b2b-smart-commerce-platform-forfree-zones/.

[43] P. Bhunia, "Government of Dubai to develop world's first gate-less border using biometrics and Blockchain," 2017. [Online]. Available: https://opengovasia.com/government-of-dubai-to-develop-worlds-firstgate-less-border-using-biometrics-and-blockchain/.

[44] “Global Blockchain Council.” [Online]. Available: https://www.dmcc .ae/about-us/global-blockchain-council.

[45] "Smart Dubai Global Blockchain Challenge.” [Online]. Available: https://www.smartdubai.ae/newsroom/news/smart-dubai-s-3rd-globalblockchain-challenge.

[46] O. Brytskyi, "Lessons to learn from the UAE in blockchain healthcare." [Online]. Available: https://espeoblockchain.com/blog/blockchainhealthcare. [Accessed: 11-Oct-2020].

[47] J. Bourne, "Dubai Multi Commodities Centre to launch 'crypto valley' ecosystem,” 2020. [Online]. Available: https://blockchaintechnologynews.com/2020/01/dubai-multi-commodities-centre-to-launch-cryptovalley-ecosystem/. [Accessed: 11-Oct-2020].

[48] S. Das, "A South Korean Province Used Blockchain Tech for Resident Voting.” [Online]. Available: https://www.ccn.com/south-koreanprovince-used-blockchain-tech-resident-voting/. [Accessed: 05-Oct2020].

[49] R. Meyer, "The City of Seoul Will Create a Cryptocurrency for Citizen Rewards,” 2019. [Online]. Available: https://www.coindesk.com/thecity-of-seoul-will-offer-blockchain-services-this-fall. [Accessed: 15Oct-2020].

[50] Data61, "Distributed Ledgers - Scenarios for the Australian economy over the coming decades,” 2017.

[51] J. Dewey, Blockchain \& Cryptocurrency Regulation. 2019.

[52] M. Al-Essa, "The Impact of Blockchain Technology on Financial Technology (FinTech),” 2019.

[53] A. Alketbi, Q. Nasir, and M. A. Talib, "Blockchain for government services-Use cases, security benefits and challenges," in 2018 15th Learning and Technology Conference, L and T 2018, 2018, pp. 112119. 